\title{
The Effect of Mere Touch on Perceived Ownership
}

\author{
JOANN PECK \\ SUZANNE B. SHU*
}

This research finds that merely touching an object results in an increase in perceived ownership of that object. For nonowners, or buyers, perceived ownership can be increased with either mere touch or with imagery encouraging touch. Perceived ownership can also be increased through touch for legal owners, or sellers of an object. We also explore valuation of an object and conclude that it is jointly influenced by both perceived ownership and by the valence of the touch experience. We discuss the implications of this research for online and traditional retailers as well as for touch research and endowment effect research.

\begin{abstract}
Captain Jean-Luc Picard: It's a boyhood fantasy. . . . I must have seen this ship hundreds of times in the Smithsonian but I was never able to touch it.
\end{abstract}

Lieutenant Commander Data: Sir, does tactile contact alter your perception?

Captain Jean-Luc Picard: Oh Yes! For humans, touch can connect you to an object in a very personal way.

\section{(From Star Trek: First Contact)}

$\mathrm{I}$ n 2003, the Illinois state attorney general's office issued a warning for holiday shoppers to be cautious of retailers who encourage them to hold objects and imagine the objects as their own when shopping. The basis of this warning was presumably that the combination of physically holding the object and ownership imagery may lead to unplanned or unnecessary purchases. Central to both the attorney general's warning and the Star Trek quote above is the concept

*Joann Peck is assistant professor of marketing at the University of Wisconsin-Madison School of Business, 3114 Grainger Hall, 975 University Avenue, Madison, WI 53706 (jpeck@bus.wisc.edu). Suzanne B. Shu is assistant professor of marketing at the UCLA Anderson School of Management, 110 Westwood Plaza, Los Angeles CA 90095 (suzanne .shu@anderson.ucla.edu). Correspondence: Joann Peck. The authors acknowledge the helpful input of the editor, associate editor, and reviewers. This research was funded, in part, by a grant from the University of Wisconsin-Madison Graduate School. The authors contributed equally to this research. Order of authorship was determined by random draw. The authors would like to thank Victor Barger, Kurt Carlson, Ty Henderson, Priyali Rajagopal, and Jennifer Wiggins Johnson for comments on earlier drafts of this research.

John Deighton served as editor and Stephen Nowlis served as associate editor for this article.

Electronically published March 24, 2009 of touch and its connection to ownership and valuation. Is the Illinois attorney general's warning valid-does holding an object and imagining that it is yours influence how much the object is valued? More generally, does mere touch influence the feeling of ownership and the valuation of an object?

Research on the sense of touch or haptics has increased in the marketing literature, possibly encouraged by the rise of online shopping where marketers are interested in how to compensate consumers for touch when it is unavailable (Peck and Childers 2007). Previous research in marketing has examined product category differences and found that some product categories encourage touch more than others (e.g., Grohmann, Spangenberg, and Sprott 2007; McCabe and Nowlis 2003; Peck and Childers 2003a). The sense of touch excels at obtaining texture, hardness, temperature, and weight information (Klatzky and Lederman 1992, 1993). If a product category varies in a diagnostic way on one of or more of these attributes, consumers will be more motivated to touch the product prior to purchase to ascertain specific attribute information (please see Peck [2009] for a review of haptic research in marketing). In addition to examining specific instrumental product information through touch, some research has investigated and found the experience of touching a pleasantly valenced object can influence persuasion, even if the touch element provides no information regarding the product (Peck and Wiggins 2006). However, the question of whether merely touching an object influences a consumer's perception of ownership and the amount they are willing to pay for an object has not been investigated.

Twenty-five years of research has shown that consumers' valuation of an object increases once they have taken ownership of it, a finding commonly known as the endowment effect (Kahneman, Knetsch, and Thaler 1990; Knetsch and Sinden 1984; Thaler 1980). The effect has been replicated 
in a variety of settings and with a variety of objects, including lottery tickets, mugs, pens, and chocolate bars (Franciosi et al. 1996; Johnson et al. 1993; Kahneman et al. 1990; Knetsch and Sinden 1984). One feature of nearly all endowment effect experiments is that the buyers (nonowners) and sellers (owners) have the opportunity to physically hold the object being traded. In the endowment literature, no previous work has directly considered whether the actual object touch inherent in these studies influences the perception of ownership and the valuation of the object.

We contribute to both the haptic literature, by demonstrating that touch does affect perceived ownership, and the object valuation literature, by introducing two new measures that operate as mediators. While ownership is considered to be critical to the endowment effect, it has generally been manipulated in prior endowment studies through legal ownership with sellers, who own the object, and buyers, who do not. An exception to this is recent work by Morewedge et al. (2006), in which ownership for both buyers and sellers is manipulated through prior ownership of an identical object. This form of prior ownership is a different construct than the perceived ownership we explore in this article.

In our studies, we introduce the empirically related but conceptually distinct construct of perceived ownership (Beggan 1992; Pierce, Kostova, and Dirks 2003) and directly measure this construct. In four studies, we find that the opportunity to touch an object increases the feeling of perceived ownership of that object and that the valuation of the object is also increased when the touch experience provides either neutral or positive sensory feedback.

Our first study focuses only on nonowners (buyers). Marketers often find it difficult to apply the findings of the endowment effect to consumer applications since most consumers are in the role of buyers rather than sellers; the ability to increase the perception of ownership and hence valuation among potential buyers would be a useful tool in many situations. Since buyers do not own the object, the question we asked was whether we could increase perceived ownership of an object in the absence of actual legal ownership and thereby increase object valuation. We manipulate whether touch is possible and we find that merely touching an object can increase a nonowner's feeling of perceived ownership and consequently object valuation. For half of the participants, we also use ownership imagery to manipulate the feeling of ownership by having the buyers imagine that the object is theirs. We find that ownership imagery is especially effective when touch is unavailable.

In our second study, we use only sellers or legal owners of an object and find that, similar to our buyers in study 1, for the sellers (owners), mere touch increases perceived ownership and valuation. Our third and fourth studies use traditional endowment effect methodology with both buyers (nonowners) and sellers (owners). We manipulate whether object touch is possible in order to further investigate the influence of touch on the perception of ownership and the valuation of an object. We find that touch directly influences perceived ownership and that the valence of the touch (whether pleasant or not), together with perceived ownership, influences object valuation.

The primary contribution of our research is in establishing that merely touching an object increases an individual's perceived ownership of the object. Our research also contributes to the valuation literature by introducing a measure of perceived ownership and noting its relationship to object valuation. In addition, we measure an individual's affective reaction toward an object. More specifically, we show that perceived ownership and affective reaction can mediate the effect of touch on valuation, relationships that have been previously suggested in the literature but have not been empirically tested. Besides the theoretical contributions of this research, this research has direct managerial implications for both traditional retailers and various nontouch media such as Internet and catalog retailers. The next section details the theory and is followed by the four studies. The last section discusses the contribution of this research to theory, and, finally, the implications of this research for managers are presented.

\section{THEORY AND HYPOTHESES}

\section{Perceived Ownership and Touch}

Our primary research motivation is to understand how merely touching an object influences perceived ownership and the valuation of an object. Previous work has established that the opportunity to touch can increase unplanned purchasing (Peck and Childers 2006) and also the willingness to donate time or money to a nonprofit organization (Peck and Wiggins 2006) but has not considered its effects on ownership or valuation. Increases in valuation have been documented for legal owners of an object through work on the endowment effect (Kahneman et al. 1990). Based on this relationship between ownership and valuation, we start by investigating the connection between touch and feelings of ownership.

Individuals may feel ownership of an object without actually owning it. Psychological ownership (Pierce et al. 2003) is distinct from legal ownership and is characterized by the feeling that something is "mine." For example, employees in an organization may develop feelings of ownership toward the organization (Pierce, Kostova, and Dirks 2001, 2003), and young children may feel ownership toward songs and maintain that the songs are "theirs" if they hear the songs first (Isaacs 1933). Many conflicts of infants, toddlers, and preschoolers are related to possessive behavior and ownership (Furby 1978, 1980), with children clearly asserting that an object is "mine!" even in the absence of actual or legal ownership. Since actual ownership leads to a greater valuation of an object, it follows that psychological or perceived ownership will also lead to an increase in valuation, even in the absence of actual ownership.

It is worth noting that perceived ownership, as used in this article, is conceptually different from legal ownership, which has typically been manipulated in the endowment effect literature. While we believe that legal ownership and 
perceived ownership are closely related (i.e., legal owners will have higher perceived ownership than legal nonowners), we also believe that perceived ownership can be affected through routes other than legal ownership-touch being one of them. Previous literature has suggested concepts similar to perceived ownership, such as anticipatory possession or pseudo-endowment (Ariely and Simonson 2003; Carmon, Wertenbroch, and Zeelenberg 2003). However, we believe we are the first to directly measure perceived ownership and statistically test its relationship to valuation.

We hypothesize that being able to touch an object will increase the feeling of perceived ownership relative to not being able to touch the object. In a comprehensive review paper on psychological ownership (Pierce et al. 2003), the antecedents of psychological ownership are discussed. These include the ability to control the object, coming to know the object intimately, and investing the self in the object. In the typical endowment procedure, participants rarely come to know the object intimately and are not likely to invest much of themselves in the target, especially given the "instant endowment" effect, where individuals value an object more almost instantly upon owning it (Kahneman et al. 1990). However, participants do have the ability to control the object, which has been found to increase feelings of psychological ownership (Furby 1980; Rudmin and Berry 1987). Furby (1980) notes that a salient feature of possession or ownership is the right to control the use of an object, both a direct physical control over the object and also a control over who else can use it. Direct physical control of an object is possible when an individual can touch an object. Building upon these findings regarding physical control and proximity leading to stronger feelings of attachment and ownership, we expect that feelings of perceived ownership will be stronger when physical touch of the object is available. Hypothesis 1 follows:

H1: The ability to touch an object will lead to greater perceived ownership of the object.

We also expect that the increased perceived ownership that comes from the ability to touch an object will lead to greater valuation of the object in most cases. The notion of ownership is central to the endowment effect. Given the "instant endowment effect," it appears that the simple act of owning the object, even if only for a moment, triggers feelings of loss when faced with the option of selling. The sense of loss increases as ownership is strengthened; a longer period of ownership increases the valuation of an object significantly (Strahilevitz and Loewenstein 1998; Wolf, Arkes, and Muhanna 2005). Our hypothesis that merely touching an object will lead to greater perceived ownership, combined with previous findings that link ownership to higher valuation of an object, suggest that, for most objects, the ability to touch will also lead to a greater valuation of an object. Valuation may not increase if touching an object results in negative sensory feedback, as discussed later.

\section{Perceived Ownership through Imagery and Touch}

Besides using touch as a way to increase perceived ownership, we expect that we can also increase the feeling of ownership through ownership imagery. Although it was not a focus of their research, Carmon and Ariely (2000) found that the buying prices and selling prices of basketball tickets of students who actually owned the tickets did not differ from those of students who were asked to imagine that they did. Sen and Johnson (1997) did not manipulate perceived ownership of an object but did manipulate possession. They used coupons for restaurants and found that having a coupon for a product influenced preference for that option. Johnson, Häubl, and Keinan (2007) were able to increase valuation among buyers without actual ownership by asking them to focus on positive aspects of the exchange; in doing so, they were able to find changes in valuation without ownership. Would ownership imagery increase feelings of perceived ownership and hence valuation of objects even for buyers (nonowners)?

It is not clear how ownership imagery and mere touch will interact. While we expect ownership imagery to increase valuation among buyers (nonowners), and we expect touch to also have a positive effect on both perceived ownership and valuation consistent with hypothesis 1 , it is not clear that the two effects are necessarily additive. Schlosser (2003, 2006) revealed that object interactivity in the context of virtual objects produces more vivid mental images compared to text or static pictures of an object. If object interactivity through touch automatically encourages mental images, it may be that imagery instructions will not further increase feelings of ownership or valuation of an object when the opportunity to touch is already present. However, when touch is unavailable, it is likely that ownership imagery can compensate for actual product touch and valuation of an object will increase compared to the no-imagery condition. This leads to our hypothesis 2 :

H2: When touch is unavailable, mental imagery encouraging ownership will increase an individual's perceived ownership of an object, but when touch is available, ownership imagery will not have an effect.

To summarize our first two hypotheses, we predict that both touch and ownership imagery can independently increase perceived ownership of an object. We test these hypotheses in study 1 .

\section{STUDY 1}

\section{Overview and Method}

The 2003 Illinois attorney general warning is directed toward buyers (nonowners), not sellers, so, in this study, we used only buyers and manipulated both the opportunity to touch and the use of ownership imagery to test hypotheses 1 and 2. The design of study 1 was a 2 (touch: touch, no touch) $\times 2$ (ownership imagery: imagery, no imagery) $\times$ 
TABLE 1

STUDY 1: PERCEIVED OWNERSHIP AND VALUATION BY OWNERSHIP IMAGERY AND TOUCH CONDITION

\begin{tabular}{|c|c|c|c|c|c|c|c|c|}
\hline & \multicolumn{3}{|c|}{ No ownership imagery } & \multicolumn{3}{|c|}{ Ownership imagery } & \multirow{2}{*}{$\begin{array}{c}\text { No touch } \\
\text { (Total } \\
n=119)\end{array}$} & \multirow{2}{*}{$\begin{array}{c}\text { Touch } \\
\text { (Total } \\
n=112)\end{array}$} \\
\hline & $\begin{array}{l}\text { No touch } \\
(n=60)\end{array}$ & $\begin{array}{l}\text { Touch } \\
(n=54)\end{array}$ & $\begin{array}{c}\text { No imagery } \\
\text { (Total } n=114)\end{array}$ & $\begin{array}{l}\text { No touch } \\
(n=59)\end{array}$ & $\begin{array}{l}\text { Touch } \\
(n=58)\end{array}$ & $\begin{array}{c}\text { Imagery } \\
(\text { Total } n=117)\end{array}$ & & \\
\hline \multicolumn{9}{|l|}{ Perceived ownership: } \\
\hline Product 1: Slinky & $2.76^{\mathrm{a}, \mathrm{m}}$ & $3.34^{\mathrm{a}}$ & $3.05^{9}$ & $3.70^{\mathrm{m}}$ & 3.41 & $3.56^{\mathrm{g}}$ & 3.20 & 3.37 \\
\hline Product 2: mug & $2.74^{b, n}$ & $3.39^{b}$ & $3.07^{\mathrm{h}}$ & $3.76^{n}$ & 3.56 & $3.66^{\mathrm{h}}$ & 3.22 & 3.47 \\
\hline Total & $2.75^{\mathrm{c}, \mathrm{o}}$ & $3.36^{c}$ & $3.06^{i}$ & $3.73^{\circ}$ & 3.49 & $3.61^{i}$ & 3.21 & 3.43 \\
\hline \multicolumn{9}{|l|}{ Valuation: } \\
\hline Product 1: Slinky & $1.88^{\mathrm{d}, \mathrm{p}}$ & $2.86^{d}$ & $2.37^{j}$ & $2.79^{p}$ & 2.61 & $2.70^{j}$ & 2.31 & 2.74 \\
\hline Product 2: mug & $3.58^{\mathrm{e}, \mathrm{q}}$ & $3.90^{\mathrm{e}}$ & $3.74^{\mathrm{k}}$ & $4.38^{\mathrm{q}}$ & 4.08 & $4.23^{k}$ & 3.96 & 3.98 \\
\hline Total & $2.73^{\mathrm{f}, \mathrm{r}}$ & $3.38^{i}$ & $3.06^{\prime}$ & $3.59^{r}$ & 3.34 & $3.47^{1}$ & 3.16 & 3.36 \\
\hline
\end{tabular}

NOTE.-Note that in study 1 , all participants were buyers (nonowners). All pairs with the same superscript letter are significantly different at $p<.05$.

2 (product: Slinky, mug) with the first two factors manipulated between subjects and the third factor within subjects. The two objects used in the experiment, a traditional metal Slinky and a mug, were chosen to be very familiar to the participants so that there would be minimal information learned by touching the objects directly. Mugs are commonly used in endowment studies, and the Slinky was chosen since it is a haptically rich object that participants enjoyed touching as determined by a pretest. Two hundred and thirty one undergraduate students at the University of Wisconsin-Madison participated in small groups of between five and ten. A participant entered the room where the two products were placed on a table in front of them no more than 2 feet away. Each participant was given a timer and instructed how to use it. Subjects filled out the questionnaire and were thanked and debriefed.

Independent Variables. The touch and no-touch conditions were manipulated by asking participants in the notouch condition to not touch the products, while those in the touch condition were explicitly asked to do so. For those participants in the ownership imagery condition, the instructions had them set the timer for a minute and to "imagine taking the product home with you. Where would you keep it? What would you do with it?" In the no-imagery condition, participants were instructed to also set the timer for 1 minute and use the minute to evaluate the product. The order of products (Slinky, mug) was counterbalanced across subjects, and no order effects were found, so this factor was collapsed. We also included the style-of-processing scale (Childers, Houston, and Heckler 1985), which measures an individual difference in imagery ability. We were concerned that some individuals would be more proficient at mental imagery, and this could influence our results. Because of this, the style-of-processing scale was included as a covariate but was not significant.

Dependent Measures. Our primary dependent variables were perceived ownership and the valuation (in dollars) of the objects. Perceived ownership was measured with three items- "I feel like this is my Slinky/Mug," "I feel a very high degree of personal ownership of the Slinky/Mug," and "I feel like I own this Slinky/Mug"—each on a 7-point scale anchored by endpoints "strongly disagree" and "strongly agree" $(\alpha=.96$ for product 1 and $\alpha=.97$ for product 2 ). These items were adapted from a measure of psychological ownership used in workplace settings (Pierce et al. 2001). All participants were buyers, with no one actually owning either of the specific products in the experiment.

For valuation of the products, participants were given the choice of values between $\$ 0$ and $\$ 6$ in increments of $\$ 0.25$ for the Slinky. Because a pretest indicated that the mug was valued more by individuals, the valuation scale for the mug was in $\$ 0.25$ increments from $\$ 0$ to $\$ 9$. Since our intention was not to compare the valuation across the products, this difference does not affect our results. As expected, when valuation was the dependent variable, the only significant within-subject factor was product, with the mug assigned a greater value than the Slinky $(M$ 's $=\$ 3.97$ and $\$ 2.52$; $F(1,227)=176.7, p<.001)$.

\section{Results}

Our goals for study 1 were to understand the effect of touch on perceived ownership (hypothesis 1) and valuation, and the effect of ownership imagery on perceived ownership in relation to touch (hypothesis 2). An ANOVA reveals a significant interaction between touch and ownership imagery for both perceived ownership $(F(1,227)=5.80$, $p=.02)$ and valuation of the products $(F(1,227)=$ $14.71, p<.001)$. Hypothesis 1 states that the ability to touch will lead to greater perceived ownership. Specific contrasts support hypothesis 1 . Within the no-imagery condition, perceived ownership in the touch condition was significantly greater than perceived ownership in the no-touch condition for both products ( $M$ 's of 3.36 and $2.75 ; F(1,227)=$ 7.94, $p=.005$; see table 1 , top half, and fig. $1 A)$. Although not specifically hypothesized, we expected that mere touch would also increase valuation of the objects. Specific contrasts again reveal that valuation of the object was greater in the touch, no-imagery condition as compared to the notouch, no-imagery condition $\left(M^{\prime} \mathrm{s}=3.38\right.$ and 2.73; 
FIGURE 1

STUDY 1: $A$, PERCEIVED OWNERSHIP (1-7) BY TOUCH AND IMAGERY CONDITIONS; $B$, VALUATION (\$) BY TOUCH AND IMAGERY CONDITIONS

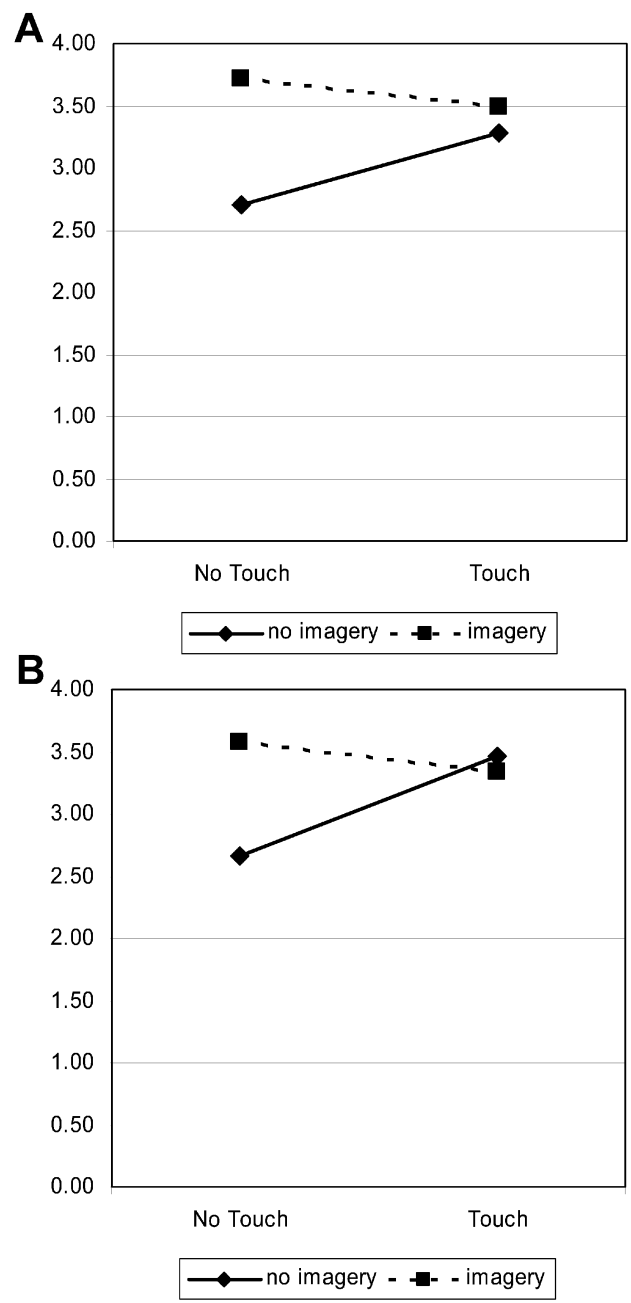

$F(1,227)=12.41, p=.001$; see table 1 , bottom half, and fig. 1B).

Our second hypothesis states that when touch is unavailable, mental imagery encouraging ownership will increase an individual's perceived ownership of an object, but when touch is available, ownership imagery will not have an effect. As reported, the interaction of touch and ownership imagery was significant for both perceived ownership and valuation. Using planned contrasts, when touch was not available, ownership imagery significantly increased both perceived ownership and valuation for the products compared to the no-ownership imagery condition (see table 1 for means, fig. 1 for a graph) as predicted. Specifically, in the no-touch condition, perceived ownership increased from 2.75 to 3.73 from the no-imagery to the ownership imagery condition $(F(1,227)=18.88, p<.001)$, and valuation in the no-touch condition increased from $\$ 2.73$ to $\$ 3.59$ with imagery $(F(1,227)=23.58, p<.001)$.

When touch was available, ownership imagery did not increase the perceived ownership or valuation of the products compared to the no-ownership-imagery condition, again, as predicted. Within the touch conditions, perceived ownership in the imagery (3.49) versus no-imagery (3.36) condition was not significantly different $(F(1,227)=.74$, $p=.39)$. Similarly, within the touch conditions, valuation of the products in the ownership imagery versus the noimagery condition was not significantly different (\$3.34 vs. $\$ 3.38 ; F(1,227)=.40, p=.53)$. As predicted, ownership imagery had a significant effect when touch was not available, but the addition of ownership imagery when touch was already available had little or no effect.

Finally, although not predicted, we obtained a significant main effect of ownership imagery on both perceived ownership ( $M$ 's of 3.06 and 3.61 for the no-ownership imagery condition and imagery condition, respectively; $F(1,227)=$ $43.26, p<.001)$ and valuation $(M$ 's of $\$ 3.06$ and $\$ 3.47$; $F(1,227)=8.59, p=.004)$.

\section{Discussion of Study 1}

Overall, it was found in study 1 that for buyers, where actual ownership was absent, object touch led to greater perceived ownership (hypothesis 1), which in turn led to higher valuation of the object, among individuals not instructed to use imagery. In addition, perceived ownership and valuation of an object were both increased by having buyers use ownership imagery. This was especially effective in the no-touch condition, with the difference between the presence and absence of imagery on both perceived ownership and valuation of the objects being significantly different (hypothesis 2). Either touch or ownership imagery increased perceived ownership and valuation, but the effect was not additive. Study 1 focused only on nonowners (buyers). In Study 2, we were curious if we could increase perceived ownership through touch even in the presence of legal ownership. Since traditional endowment experiments include touch but not ownership imagery, Study 2 uses only owners (sellers) and manipulates touch to test hypothesis 1 .

\section{STUDY 2}

\section{Overview and Method}

The purpose of study 2 was to examine the effect of touch on perceived ownership (hypothesis 1) and valuation using only sellers or owners. The design of study 2 was a 2 (touch: touch, no touch) between-subjects study. The object used in the experiment, a mechanical pencil with a rubberized grip, was chosen to be very familiar to the participants so that there would be no additional information to be learned by touching the object. This was confirmed in a pretest. Individuals were asked whether they had enough information to evaluate the pencil in both a touch and a no-touch condition. On a 7-point scale, with endpoints strongly dis- 
agree (1) and strongly agree (7), there was no difference between the two conditions (touch condition, $M=3.85$; notouch condition, $M=4.06 ; t(142)=.70, p=.48)$.

All participants were told that they owned a pencil and that it was theirs to keep unless they chose to sell it. After completing the questionnaire, final selling prices for the pencils were determined by random draw, a process designed to elicit true valuations from participants (Becker, DeGroot, and Marshak 1964). After the final price was established, all participants left the experiment with either the mechanical pencil or cash according to the decisions they had made during the valuation process. Participants were 71 undergraduate students in Southern Methodist University business school's introductory and advanced marketing classes. Participants completed the exercise in groups of up to 40 at one time, either in exchange for course credit or as an inclass exercise.

Independent Variable. Participants in the touch condition received the mechanical pencil before the valuation procedure and were encouraged to touch it directly before valuing it. All participants in this condition touched the pencil. They were told that the pencil was theirs to keep or sell. In the no-touch condition, the pencils were displayed in the front of the room and described in detail, but the participants were not able to touch them. Sellers in this notouch condition were told that they had "official ownership" of one of the pencils, which they could keep or sell.

Dependent Measures. Our primary dependent variables were perceived ownership ( $\alpha=.97)$ and the valuation (in dollars) as in study 1 . Valuation was measured by participants indicating their willingness to sell the object at each possible price along a continuum of $\$ 0$ to $\$ 6$ (at $\$ 0.25$ intervals).

\section{Results and Discussion of Study 2}

Our first hypothesis predicts that mere touch will increase perceived ownership. Even for sellers, who actually own the object, this was supported. There was a main effect of touch, with owners who could touch feeling significantly greater perceived ownership than those who could not touch $\left(M^{\prime}\right.$ 's of 5.04 and $4.18 ; F(1,69)=5.88, p=.02$ ), supporting hypothesis 1 . Parallel results were found with valuation. Owners who could touch compared to those who could not touch valued the pencil significantly more ( $M$ 's of $\$ 2.96$ and $\$ 2.09$; $F(1,69)=12.30, p=.001)$.

The first two studies found that mere touch can increase perceived ownership for buyers or nonowners (study 1) and for sellers or owners (study 2). In both studies, touch also increased the valuation of the object. Since traditional endowment experiments include both buyers (nonowners) and sellers (owners) simultaneously, in studies 3 and 4 we include both and we also delve deeper into the process through which mere touch and perceived ownership influence valuation of an object.

\section{Touch Valence and Affective Reaction}

Thus far, we have focused on the effects of touch on perceived ownership. However, we also expect that touch can influence a person's affective reaction toward an object. Touching an object leads to an immediate, automatic emotional response toward the object separate from an increase in liking due to simply having more information about the object. While touch is predicted to have a consistently positive impact on perceived ownership (hypothesis 1), its positive or negative effects on an individual's affective reaction toward an object are dependent on the valence of the touch experience. Support for an affective reaction through touch is found in a paper by Peck and Wiggins (2006). Across three studies, affect through touch consistently influenced judgments. For example, in one study, participants received a pamphlet requesting a donation of time and money to a local arboretum. The pamphlet contained either a manipulation eliciting a positive touch sensation (a feather), a neutral sensation (tree bark), or a negative sensation (sandpaper). The pamphlet containing the positive manipulation elevated attitudes toward the message, while the negative manipulation depressed attitudes.

Endowment effect research also provides some evidence that receiving objects perceived as unpleasant leads to a negative affective reaction toward the object, as evidenced by lower valuation. For example, Lerner, Small, and Loewenstein (2004) found that an individual's negative emotional state (such as disgust or sadness) can lower valuation for endowed objects, and work on possession loss aversion (Brenner et al. 2007) shows lower selling prices for negative items.

The ability to touch a pleasurable object will lead to a stronger affective reaction toward the object, which contributes to feelings of loss if an object is sold. However, if the object is less pleasant to touch, the negative affective reaction associated with the object may lead to relief when the object is sold, and would not necessarily increase valuation for the object. We expect that positive or neutral touch experiences will increase valuation of an object through both a greater perceived ownership and a more positive affective reaction to the object. However, if the touch experience is less positive, we expect that touching the object will still result in an increase in perceived ownership (hypothesis 1), but it will not necessarily increase valuation since the affective reaction from touching would decrease. This leads to our final hypothesis:

H3: An object that provides neutral or pleasant haptic sensory feedback will increase valuation of the object by increasing both perceived ownership of the object and by providing a more positive affective reaction to the object.

In other words, we hypothesize that the affective reaction toward an object and perceived ownership have separate mediating effects. If touching an object results in neutral or positive sensory feedback, we expect that both perceived ownership of the object and affective reaction will increase, 
which will also increase the valuation of an object, as in studies 1 and 2. If touching an object results in negative sensory feedback, we expect that perceived ownership increases as a result of mere touch but that affective reaction to the object does not increase. Thus, we do not provide a specific hypothesis for objects with negative sensory feedback, as the effect of touch on valuation for such objects is dependent on the trade-off between these two opposing effects. We also predict that these constructs operate independently of each other and are specific to the object being touched.

One implication of these hypotheses is that valuation of an object that is neutral or pleasurable to touch will be greater when touch is allowed than when it is not. This effect becomes even stronger when the effects of actual legal ownership are accounted for. Previous research on the endowment effect has suggested that sellers focus more closely on the aspects of the object, especially its affect-rich (hedonic) characteristics, than do buyers (Carmon and Ariely 2000; Dhar and Wertenbroch 2000). More recently, a strong case has been made that the affective attachment experienced by sellers is a strong driver of the endowment effect due to the role of emotion as an important component of loss aversion (Ariely, Huber, and Wertenbroch 2005; also see Rottenstreich and Shu [2004] for a review of the role of affect in loss aversion). Based on these findings for affect and loss aversion, it is predicted that positive affective reaction toward an endowed object directly increases valuation.

\section{STUDY 3}

\section{Overview and Method}

The purpose of study 3 was to examine hypothesis 3 . The design was a 2 (touch condition: touch/no touch) $\times 2$ (role: buyer [nonowner]/seller [owner]), with both factors manipulated between groups. Our primary dependent variables were perceived ownership, affective reaction, and the valuation of the object. The object used in the experiment, a traditional metal Slinky, was chosen because it would be very familiar to the participants, so there would be no additional information to be learned by touching the object directly. We deliberately chose a haptically rich object that participants enjoyed touching. In a pretest, 34 participants were asked to touch the Slinky and indicate "how pleasant was this to touch" on a scale from 1 (not at all pleasant) to 7 (extremely pleasant). The mean of 6.3 indicated that this product was quite pleasant to touch.

Participants were 401 undergraduate students in an introductory marketing class at the University of Wisconsin-Madison. The research was conducted outside of class as an extra-credit opportunity and took approximately 20 minutes. Participants completed the exercise in groups of about 25.

Consistent with traditional endowment effect studies (Kahneman et al. 1990), an induced value market example was introduced to familiarize participants with the trading process. Participants were divided into sellers and buyers and completed the induced value market as a warm-up exercise. To control for possible income effects or cash constraints, those in the "buyer" condition are actually choosers. Choosers indicate their preference between receiving cash or the object at each possible price. Previous work on the endowment effect indicates minimal difference between buyers and choosers (Kahneman et al. 1990). We will refer to these participants as buyers throughout the article for expositional simplicity.

Participants were then instructed that the next decisions they made to buy and sell in this market would be completed for real money. These decisions were the focus of our experiment. The item to be traded (here, a metal Slinky) was introduced to the participants. Sellers (owners) were told that they owned a Slinky and that it was theirs to keep unless they chose to sell it, while buyers (nonowners) were told that they do not yet own a Slinky but would have the option to receive one. They then recorded their valuations by indicating their willingness to sell or buy the object at each possible price along a continuum of $\$ 0$ to $\$ 6$ (at $\$ 0.25$ intervals). After completing the remaining questionnaire items, final selling prices for the Slinky toys were determined by random draw. This valuation elicitation process is consistent with Becker et al. (1964) procedures and was designed to elicit true valuations from the participants. After the final price was established, all participants left the experiment with either the Slinky or cash according to the decisions they had made during the valuation process.

Independent Variables. The buyer (nonowner)/seller (owner) role conditions were randomly assigned to individuals as they entered the room. Participants in the touch condition received the Slinky and played with it before the valuation procedure. In the no-touch condition, individuals were given the Slinky still inside its square box packaging; they were allowed to touch the packaging but were not able to directly touch the Slinky itself. There was also a Slinky outside of the package sitting in the front of the room for the participants to see. None of the students in the no-touch condition attempted to remove the Slinky from the packaging. Whereas sellers (owners) in each condition were told that the object they were holding was theirs to keep or sell, the buyers in each condition were also asked to hold and touch the object so that both groups had equivalent contact with the product.

Dependent Measures. Perceived ownership was measured with three items as in the previous studies $(\alpha=.96)$. The affective reaction measure was collected on a subset of participants $(n=130)$ in order to examine the process by which this measure mediates valuation. Affective reaction was measured with a scale designed by Derbaix (1995) and that was also used in Peck and Wiggins (2006). Participants were told, "here is a list of emotional reactions you may have experienced. Please indicate how much you felt each of these emotional reactions." This was followed by a list of seven reactions (interested, moved, captivated, delighted, 
enthusiastic, appealed, and amused), with endpoints at "not at all" (1) and "a lot" (7) $(\alpha=.88)$. Items were averaged for an affective reaction scale with a range of $1-7$. In a separate pretest, a factor analysis with varimax orthogonal rotation revealed that there was no correlation between perceived ownership and affective reaction. The three perceived ownership items loaded highly on one factor, and the seven affective reaction items loaded highly on a second factor.

\section{Results}

Means for this study are provided in table 2. Planned contrasts revealed that participants who were able to touch felt more perceived ownership than those who were not able to touch, supporting hypothesis 1 ( $M$ 's of 3.27 and 2.84; $F(1,397)=8.99, p=.003)$. Not surprisingly, we also find a significant positive relationship between legal ownership and perceived ownership. With perceived ownership as the dependent variable, planned contrasts reveal a significant main effect of buyer/seller role, with sellers feeling more perceived ownership than buyers ( $M$ 's of 3.91 and 2.20; $F(1,397)=129.2, p<.001)$. Planned contrasts also revealed that the basic endowment effect was found with sellers valuing the item more than buyers ( $M$ 's of $\$ 2.52$ and $\$ 1.59$; $F(1,397)=66.26, p<.001)$.

We predicted that an object that provided pleasant haptic sensory feedback such as a Slinky would not only increase perceived ownership of the object but would also result in a more positive affective reaction to the object, which would jointly increase valuation of the object (hypothesis 3). Both affective reaction and valuation of the object were significantly increased in the touch versus the no-touch condition. Specifically, affective reaction increased from 3.58 to 4.13
$(F(1,126)=5.07, p=.02)$, and valuation increased from $\$ 1.93$ to $\$ 2.18(F(1,397)=4.52, p=.03)$. Note that average valuation for the Slinky was less than that given by the buyers in study 1 . We expect that this difference is due to the longer period of time buyers spent evaluating the product in study 1 .

Based on hypothesis 3, we expected to see that mere touch could increase valuation of an object by increasing both perceived ownership and affective reaction. A series of regressions were run to test these relationships. First, the earlier findings are repeated of main effects for the buyer/seller role (nonowner/owner) and touch conditions on valuation $\left(\beta_{\text {role }}=.97, t=8.53, p<.001 ; \beta_{\text {touch }}=.25, t=2.11\right.$, $p=.04)$. Next, consistent with the results reported earlier, the owner/nonowner role and touch conditions were significantly related to perceived ownership $\left(\beta_{\text {role }}=1.75, t=\right.$ $\left.11.78, p<.001, \beta_{\text {touch }}=.44, t=2.89, p=.004\right)$, and the owner/nonowner role and touch were significantly related to affective reaction $\left(\beta_{\text {role }}=2.58, t=2.89, p=.005 ; \beta_{\text {touch }}\right.$ $=2.4, t=2.28, p=.02$ ). Next, perceived ownership and affective reaction were both significantly related to valuation $\left(\beta_{\text {own }}=.29, t=4.64, p<.001 ; \beta_{\text {affec }}=.08, t=3.63\right.$, $p<.001)$.

Finally, a regression was run with valuation as the dependent variable in which all four variables were included, and found that the relationships between valuation and the role and touch conditions became insignificant in the presence of perceived ownership and affective reaction, suggesting full mediation (see table 3, upper portion, for a summary of all regression results). Sobel tests further indicated that perceived ownership $(z=2.91, p=.004)$ and affective reaction $(z=2.14, p=.03)$ were significant mediators of touch condition on valuation. Regressions were

TABLE 2

STUDIES 3 AND 4: MEAN VALUATION, PERCEIVED OWNERSHIP, AND AFFECTIVE REACTION BY OWNERSHIP ROLE AND TOUCH CONDITION

\begin{tabular}{|c|c|c|c|c|c|c|c|c|}
\hline & \multicolumn{3}{|c|}{ Seller (owner) } & \multicolumn{3}{|c|}{ Buyer (nonowner) } & \multirow{2}{*}{$\begin{array}{l}\text { No } \\
\text { touch } \\
\text { total }\end{array}$} & \multirow{2}{*}{$\begin{array}{l}\text { Touch } \\
\text { total }\end{array}$} \\
\hline & No touch & Touch & Seller total & No touch & Touch & Buyer total & & \\
\hline \multicolumn{9}{|l|}{$\begin{array}{l}\text { Perceived ownership } \\
\qquad(1-7) \text { : }\end{array}$} \\
\hline Study 3: Slinky & $3.45^{\mathrm{g}}$ & $4.31^{g}$ & $3.91^{d}$ & 2.19 & 2.23 & $2.20^{d}$ & $2.84^{a}$ & $3.27^{a}$ \\
\hline$n$ & 82 & 125 & 207 & 82 & 110 & 192 & 164 & 235 \\
\hline Study 4: Playfoam & $3.17^{\circ}$ & $3.84^{\circ}$ & $3.51^{\prime}$ & 1.84 & 1.98 & $1.91^{\prime}$ & $2.51^{j}$ & $2.91^{j}$ \\
\hline$n$ & 60 & 111 & 171 & 58 & 105 & 163 & 118 & 216 \\
\hline \multicolumn{9}{|l|}{ Valuation (\$): } \\
\hline Study 3: Slinky & $2.25^{\mathrm{h}}$ & $2.77^{\mathrm{h}}$ & $2.52^{\mathrm{e}}$ & 1.59 & 1.59 & $1.59^{\mathrm{e}}$ & $1.93^{b}$ & $2.18^{\mathrm{b}}$ \\
\hline$n$ & 84 & 125 & 209 & 82 & 110 & 192 & 166 & 235 \\
\hline Study 4: Playfoam & 1.73 & 1.52 & $1.61^{\mathrm{m}}$ & 1.30 & 1.26 & $1.27^{\mathrm{m}}$ & 1.54 & 1.34 \\
\hline$n$ & 60 & 111 & 171 & 58 & 105 & 163 & 118 & 216 \\
\hline \multicolumn{9}{|l|}{$\begin{array}{l}\text { Affective reaction } \\
\qquad(1-7) \text { : }\end{array}$} \\
\hline Study 3: Slinky & $3.70^{\mathrm{j}}$ & $4.32^{\mathrm{j}}$ & $4.19^{f}$ & 3.45 & 3.87 & $3.75^{f}$ & $3.58^{c}$ & $4.13^{\mathrm{c}}$ \\
\hline$n$ & 16 & 56 & 70 & 16 & 42 & 58 & 32 & 98 \\
\hline Study 4: Playfoam & $3.80^{p}$ & $3.39^{p}$ & $3.53^{n}$ & 3.44 & 3.12 & $3.24^{n}$ & $3.62^{k}$ & $3.26^{k}$ \\
\hline$n$ & 60 & 111 & 171 & 58 & 104 & 162 & 118 & 215 \\
\hline
\end{tabular}

NOTE.-All pairs with the same superscript letter in the same row are significantly different at $p<.05$. 
TABLE 3

SUMMARY OF REGRESSION RESULTS REPORTED IN STUDIES 3 AND 4

\begin{tabular}{|c|c|c|c|c|c|}
\hline Variable & Regression 1 & Regression 2 & Regression 3 & Regression 4 & Regression 5 \\
\hline \multicolumn{6}{|l|}{ Study 3-positive touch: } \\
\hline Ownership condition & $\begin{array}{c}.97 \\
(p<.001)\end{array}$ & & $\begin{array}{c}.43 \\
(p=.09)\end{array}$ & $\begin{array}{c}.50 \\
(p<.001)\end{array}$ & $\begin{array}{c}.84 \\
(p<.001)\end{array}$ \\
\hline Touch condition & $\begin{array}{c}.25 \\
(p=.04)\end{array}$ & & $\begin{array}{c}-.20 \\
(p=.4)\end{array}$ & $\begin{array}{c}.13 \\
(p=.24)\end{array}$ & $\begin{array}{c}-.14 \\
(p=.6)\end{array}$ \\
\hline Perceived ownership & & $\begin{array}{c}.29 \\
(p<.001)\end{array}$ & $\begin{array}{c}.22 \\
(p=.004)\end{array}$ & $\begin{array}{c}.27 \\
(p<.001)\end{array}$ & \\
\hline Affective reaction & & $\begin{array}{c}.08 \\
(p<.001)\end{array}$ & $\begin{array}{c}.08 \\
(p=.001)\end{array}$ & & $\begin{array}{c}.11 \\
(p<.001)\end{array}$ \\
\hline \multicolumn{6}{|l|}{ Study 4-negative touch: } \\
\hline Ownership condition & $\begin{array}{c}.32 \\
(p=.002)\end{array}$ & & $\begin{array}{c}.07 \\
(p=.51)\end{array}$ & $\begin{array}{c}.07 \\
(p=.58)\end{array}$ & $\begin{array}{c}.18 \\
(p=.06)\end{array}$ \\
\hline Touch condition & $\begin{array}{c}-.12 \\
(p=.25)\end{array}$ & & $\begin{array}{c}-.05 \\
(p=.67)\end{array}$ & $\begin{array}{c}-.18 \\
(p=.08)\end{array}$ & $\begin{array}{c}-.01 \\
(p=.97)\end{array}$ \\
\hline Perceived ownership & & $\begin{array}{c}.08 \\
(p=.009)\end{array}$ & $\begin{array}{c}.07 \\
(p=.05)\end{array}$ & $\begin{array}{c}.15 \\
(p<.001)\end{array}$ & \\
\hline Affective reaction & & $\begin{array}{c}.11 \\
(p<.001)\end{array}$ & $\begin{array}{c}.11 \\
(p<.001)\end{array}$ & & $\begin{array}{c}.12 \\
(p<.001)\end{array}$ \\
\hline
\end{tabular}
touch), psychological ownership, and affective reaction toward the object.

also run in which only one of the two proposed mediators was included; if only perceived ownership was included, the ownership role condition remained significant, although the coefficient for role was significantly reduced. If only affective reaction was included, the role condition remained significant. Thus, neither perceived ownership nor affective reaction was sufficient on its own to fully mediate valuation; both constructs play an important role in determining how participants value the object.

\section{Discussion of Study 3}

Study 3 supported our predictions by finding that the ability to directly touch an object with positive sensory feedback increased perceived ownership, affective reaction, and the valuation of the object in a traditional endowment effect experiment. In addition, study 3 directly measured both perceived ownership and affective reactions toward the object and revealed that these two constructs mediate the effects of touch on valuation. The opportunity to touch an object, compared to the inability to touch, increased the perceived ownership an individual felt toward the object and increased the individual's affective reaction toward the object.

The antecedents of perceived ownership includes the ability to control an object, which includes both physical control of the object (touch) and the control of being able to decide the fate of the object such as keeping it or selling it. In most endowment effect experiments, sellers actually have legal ownership of the object, creating a baseline level of ownership for those participants. The ability to touch the object seems to boost the feeling of perceived ownership and valuation among this group. Direct measurement of perceived ownership, and its use as an empirical construct for understanding differences in valuation among groups of buyers and sellers, have previously been unexplored in most endowment effect literature.

While study 3 used a pleasurable touch object, a Slinky, as the target of the valuation, it was necessary to investigate how the role of touch influences valuation for objects that are not as pleasurable to touch to fully test our hypothesis 3. The affective reaction from touch is expected to decrease when the object being touched is less pleasurable. However, it is not predicted that less pleasurable object touch will have a negative effect on perceived ownership. To test these predicted relationships, study 4 was designed to closely mirror study 3, with one important difference: the endowed object chosen for study 3 was specifically selected to be less pleasurable to touch than the Slinky used in study 3.

\section{STUDY 4}

\section{Overview and Method}

The goal of study 4 was to investigate how the hypothesized relationships between touch, perceived ownership, affective reaction, and valuation change when the endowed object is less pleasant to touch. As in study 3, the overall design was a 2 (role: buyer [nonowner]/seller [owner]) $\times$ 2 (touch condition: touch/no touch), with both factors manipulated between groups. The object chosen, determined by a pretest to not be especially pleasant to touch, was Playfoam sculpting beads. In a pretest, 22 participants were asked to touch the Playfoam and indicate "How pleasant was this to touch?" on a scale from 1 (not at all pleasant) to 7 (extremely pleasant). The mean of 2.5 indicated that this product was not especially pleasant to touch.

This product was packaged in a 3-inch by 2 -inch clear plastic bag. Participants in the endowment study were 334 
undergraduate students at the University of WisconsinMadison enrolled in an introductory marketing class. The research was conducted outside of class as an extra credit opportunity and took approximately 20 minutes. The same endowment effect experimental methodology employed in study 3 was used here, including the Becker et al. (1964) valuation elicitation procedures.

Independent Variables and Dependent Measures. The buyer (nonowner) and seller (owner) roles were randomly assigned as the participants entered the room. Touch was manipulated by having half of the participants able to directly touch the Playfoam out of the packaging while the other half of the participants examined the Playfoam in the package with no opportunity to touch it directly. The primary dependent variables were measured as in study 3 and included perceived ownership ( $\alpha=.96)$, affective reaction $(\alpha=.86)$, and valuation of the object.

\section{Results}

Means for this study are provided in table 2. Hypothesis 1 predicted that mere touch would lead to an increase in perceived ownership. Using planned contrasts, hypothesis 1 was supported, with participants who were able to touch feeling more perceived ownership than those who were not able to touch $(M$ 's of 2.91 and $2.51 ; F(1,330)=6.66$, $p=.01$ ). As with study 3 , it was expected and found that sellers would feel more perceived ownership than buyers. Using planned contrasts, a significant main effect of role was found, with sellers feeling more ownership than buyers ( $M$ 's of 3.51 and $1.91 ; F(1,330)=104.1, p<.001)$. As expected, the endowment effect was found, with sellers valuing the Playfoam more than buyers ( $M$ 's of $\$ 1.61$ and $\$ 1.27 ; F(1,330)=10.05, p=.002)$.

The effects on valuation and affective reaction from being able to touch or not touch the Playfoam were very different from what was found in study 3 . As expected for an object that is less pleasurable to touch, the overall main effect of touch on valuation was not significant-individuals who could touch assigned a value to the Playfoam that was similar to the value assigned by those who couldn't touch ( $M$ 's of $\$ 1.34$ and $\$ 1.54 ; F(1,330)=.66, p=.42)$. Thus, the effects of touch on valuation appear to have been dampened or even reversed as compared to the study 3 findings, given the Playfoam's nature of being slightly unpleasant to touch.

While the relationship between touch and perceived ownership (hypothesis 1) was unaffected by the valence of touch, as predicted, it was expected that the effects of touching a less pleasant object would result in a less positive affective reaction as compared to touching the pleasant Slinky. Manipulation of touch had a significant main effect on affective reaction, although for this product the effect was negative instead of positive; individuals who could directly touch the Playfoam had a less positive affective reaction than those who could not $(M$ 's of 3.26 and $3.62 ; F(1,330)=6.47$, $p=.01)$. The relationship between affective reaction and valuation found in study 3 , in which greater affective re- action led to higher valuation, remained significant $(\beta=$ $.47, t=7.51, p<.001)$.

As with study 3 , it was expected that perceived ownership and affective reaction would mediate valuation. Note, however, that the mediation operates somewhat differently here, since the touch condition was not significant for valuation. Based on the analyses described, ownership role (buyer/ seller) and touch were both significantly positive predictors for perceived ownership. Ownership role and touch condition were significant for affective reaction, and the touch condition had a negative influence consistent with the unpleasant touch aspects for the product. Thus, the touch condition had two opposite effects on the mediator variables: a positive effect from touch on perceived ownership and a negative effect from touch on affective reaction to the object. If perceived ownership and affective reaction are operating as mediators for valuation, then the opposite effects of touch on these two measured variables can explain why there was no overall main effect of touch on the valuation of the Playfoam.

As with study 3, these proposed relationships were tested with a series of regressions. First, the earlier findings were repeated concerning the effects of ownership role (buyer/ seller) and touch on valuation $\left(\beta_{\text {role }}=.32, t=3.1, p=\right.$ $.002 ; \beta_{\text {touch }}=-.12$, NS). Next, consistent with the results reported earlier, the ownership role and touch conditions were significantly related to perceived ownership $\left(\beta_{\text {role }}=\right.$ $\left.1.68, t=11.3, p<.001, \beta_{\text {touch }}=.38, t=2.45, p=.02\right)$, and ownership role and touch were significantly related to affective reaction $\left(\beta_{\text {role }}=1.17, t=3.49, p=.001 ; \beta_{\text {touch }}\right.$ $=-1.02, t=2.89, p=.004)$. Next, it was found that perceived ownership and affective reaction were both significantly related to valuation $\left(\beta_{\text {own }}=.08, t=2.62, p=\right.$ $\left..009 ; \beta_{\mathrm{affec}}=.11, t=6.81, p<.001\right)$. Finally, a regression with valuation as the dependent variable and all four independent variables found that the relationships between valuation and the role and touch conditions were no longer significant in the presence of perceived ownership and affective reaction, suggesting full mediation (see table 3 , lower half, for a summary of all regression results). Sobel tests further indicated that perceived ownership $(z=2.01$, $p=.04)$ and affective reaction $(z=-2.82, p=.005)$ were significant mediators of touch condition on valuation. Regressions were also run in which only one of the two proposed mediators was included; if only perceived ownership was included, the touch condition was still marginally significant, and if only affective reaction was included, the role condition remains marginally significant. Thus, as with the Slinky, neither perceived ownership nor affective reaction is sufficient on its own to fully mediate valuation.

\section{Discussion of Study 4}

The findings from study 4 reinforce the findings of the first three studies but also provide additional insight on how touch, especially less pleasant touch, influences valuation of an object. Merely touching an object continued to have a positive effect on perceived ownership (hypothesis 1), even 
though the Playfoam was not pleasant to touch (fig. $2 A$ ). In addition, and consistent with most previous work on the endowment effect, a significant main effect of ownership role on valuation was found, with sellers valuing the product more than buyers.

The primary difference between the findings in study 4 as compared to study 3 concerns the effect of touch on affective reaction toward the object. Whereas this effect was positive for the enjoyable Slinky, the effect becomes negative for the unpleasant Playfoam, resulting in a lower affective reaction among participants who could touch the Playfoam than among those who could not (fig. 2B). The less positive affective reaction for the less pleasant object, and its resultant effect of reducing valuation among sellers who could touch the Playfoam, is consistent with the lower endowment effects found in other studies with unpleasant or emotionally contaminated objects (Brenner et al. 2007; Lerner et al. 2004). As with study 3, the combination of the perceived ownership and affective reaction measures was sufficient to fully mediate the effects of the independent variables on valuation.

\section{GENERAL DISCUSSION}

Using a variety of objects (Playfoam, Slinky toys, mugs, pencils), we investigated the role of mere touch on perceived ownership and valuation. It was found across all four studies that touch leads to increased perceived ownership, and this increase in perceived ownership then leads to an increase in valuation of an object if the object provides neutral or positive sensory feedback as in studies $1-3$. In study 1 , we considered only buyers or nonowners and found that perceived ownership, in the absence of actual legal ownership, can be increased with the use of either touch or ownership imagery. Using ownership imagery significantly increased both perceived ownership and the valuation of objects. The use of ownership imagery to increase both perceived ownership and valuation of the objects was especially effective when touch was unavailable.

These results, in which ownership imagery increased valuation among buyers, are consistent with findings in other endowment effect studies that ask buyers to focus on the desirable features of the object (Carmon and Ariely 2000; Johnson et al. 2007; Nayakankuppam and Mishra 2005). In those studies, buyers who were asked to think about positive (value-increasing) aspects of the object valued it more highly than buyers who were focused on value-decreasing aspects, or what else they could do with the money they were spending. It may be that imagining taking the object home, or even simply touching the object, spontaneously generated a similar focus on the positive elements of the object for the buyers. While giving additional instructions for buyers to focus on positive aspects of the object has previously been shown to increase valuation, such instructions for sellers have not typically been found to have an effect; one of the surprising results of our work is in how valuation for sellers can be increased through touch (studies 2 and 3 ).

In studies 3 and 4 , in which both buyers and sellers were
FIGURE 2

STUDIES 3 AND 4: $A$, PERCEIVED OWNERSHIP BY ROLE, TOUCH, AND PRODUCT TYPE; $B$, AFFECTIVE REACTION BY ROLE, TOUCH, AND PRODUCT TYPE

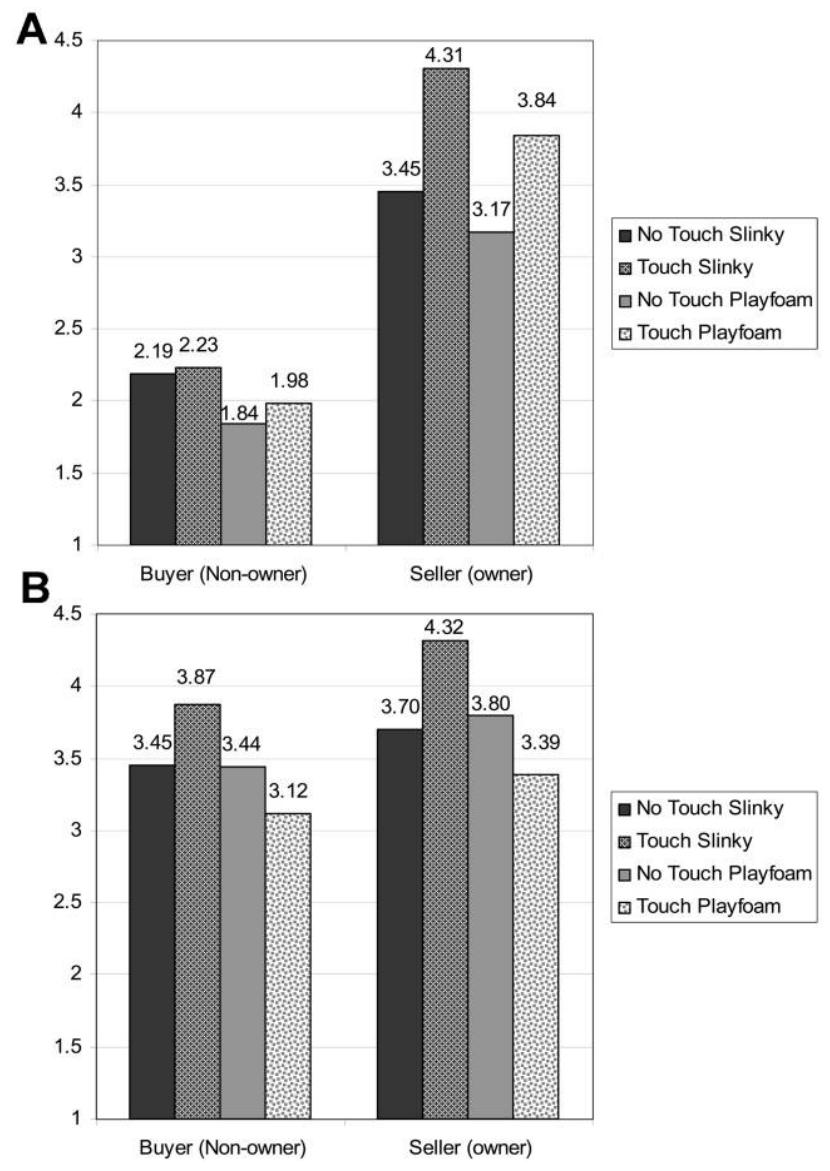

included, it was found that touch again increased perceived ownership. In addition to increasing feelings of perceived ownership, the ability to touch also influences an individual's affective reaction toward an object. For objects that were enjoyable to touch (the Slinky in study 3), an increase in perceived ownership coupled with a positive affective reaction increased valuation of the object. However, for objects that were less enjoyable to touch (the Playfoam in study 4), mere touch again increased perceived ownership, but decreased the affective reaction, so valuation was not increased as a result of mere touch.

Future research could examine the exact type of sensory feedback provided through touch and the individual's response to it. An individual difference in preference for sensory feedback from touch (termed "Need for Touch," or NFT) has been documented in previous research (Peck and Childers 2003a, 2003b). Touch that is not diagnostic for product evaluation can result in an increased affective response for individuals high in NFT (Peck and Wiggins 2006) and no differential response for individuals high or low in 
NFT (Krishna and Morrin 2008). These differential results are likely due to the type of touch sensory feedback provided. Peck and Wiggins (2006) used a soft fabric swatch and found that high-NFT individuals had a greater affective response to this touch than their low-NFT counterparts. Krishna and Morrin (2008) examined the type of touch provided by either a flimsy or firmer cup and found that both high- and low-NFT individuals preferred the firmer cup. It is likely that different types of sensory feedback (i.e., softness, firmness) differentially influence high- and low-NFT individuals. This is especially interesting since research has found that if processing resources are limited, affective reactions rather than cognitions have a greater impact on choice (Shiv and Fedorikhin 1999). More generally, while there is some research on the interaction between touch and other senses (Krishna 2006; Krishna and Morrin 2008), more research is needed in this area.

Our findings on the effects of object touch, imagery, perceived ownership, and affective reaction for object valuation generate interesting connotations for the endowment effect and, more generally, for loss aversion. The emotional experiences that can be generated through physical touch, as evidenced by the Star Trek quote at the beginning of this article, can be quite powerful and resonate well with the emotional nature of loss aversion. This may be especially true for individuals who are high in NFT; they are motivated to touch objects because of the sensory pleasure it provides, and taking away the object that provides that pleasure may be increasingly painful. For some individuals, ownership imagery may serve as a substitute source of emotional experiences connected to the object, as evidenced in study 1 .

The existence of two constructs, perceived ownership and affective reaction, which jointly mediate valuation, is a significant contribution to our understanding of the psychology that underlies the endowment effect. For example, our measure of perceived ownership provides some interesting clues for the dilemma of when a sale or exchange is actually coded as a "loss." Items that are psychologically owned by the individual incur losses when given up; high levels of perceived ownership may be the result of legal ownership, but can also be affected by time, touch, and imagery. In contrast, objects that are frequently traded (e.g., stocks, money) may be legally owned and yet low in perceived ownership, resulting in an ability to forfeit them without "feeling the loss." The importance of the perceived ownership and affective reaction measures in valuation is consistent with, but also significantly extends, recent endowment effect research on possession loss aversion (Brenner et al. 2007), emotional attachment and cognitive perspectives of ownership (Ariely et al. 2005; Ariely and Simonson 2003; Carmen, Wertenbroch, and Zeelenberg 2003), and lack of loss aversion for items that are expected to be given up (Novemsky and Kahneman 2005; Thaler 1985). Further investigation into the connections between perceived ownership, affect, and loss aversion seems a ripe area for exploration.

We were also able to demonstrate that mere touch increases perceived ownership among buyers (study 1) and sellers (study 2). However, when both buyers and sellers are included (studies 3 and 4) we find that the sellers are more influenced by touch than buyers. It could be that by simultaneously including buyers and sellers, ownership status is made more salient, especially for buyers who realize that they do not legally own an object while others in the room actually own the object. Future research should examine role salience and its effect on perceived ownership.

The 2003 Illinois attorney general's warning cautioned buyers against retailers who used both touch and imagery as a sales tactic; results for the buyers in study 1 suggest that while both are useful, ownership imagery alone can still be a powerful effect. This has important implications not only for traditional retailers (and the state attorney generals who monitor them) but also for catalog or online merchants whose customers are frequently unable to physically interact with the object being offered. For traditional retailers, our research may help explain the link between touch and impulse purchase (Peck and Childers 2006). Encouraging touch in a retail store, as Apple does for products like the iPhone, may increase the feelings of perceived ownership and influence the amount a customer is willing to pay for a product, even in the absence of ownership imagery. Offers of a "free trial" for a certain time period before the consumer is obligated to pay are also likely to increase perceived ownership, which ultimately influences product valuation. This effect may be even greater than our research suggests. In order to control for the information effects of touch while evaluating products, we deliberately chose products in which touch would not provide additional meaningful attribute information. However, for many products, being able to touch the products would provide more information, which may also increase the feeling of perceived ownership. Future research should examine products that provide both positive sensory feedback as well as information through touch input.

Online retailers who can encourage ownership imagery among potential buyers may be able to increase both perceived ownership and valuation. In the no-touch environment, ownership imagery was powerful in increasing both the feeling of ownership and the amount a consumer was willing to pay. The study 1 finding that consumers respond effectively to the combination of no touch and ownership imagery suggests a remarkable opportunity for online retailers to increase perceived ownership and purchase among this group. This ability to increase valuation among buyers, by increasing perceived ownership, is an important new contribution to the endowment effect literature. Combined with other recent endowment effect findings about methods to increase valuation among buyers, it provides useful new prescriptive advice for marketers who are looking to apply concepts from loss aversion and endowment effect theories to everyday consumer purchases.

Finally, our research supports Captain Jean-Luc Picard's claim that "For humans, touch can connect you to an object in a very personal way." In four studies, we found that mere touch does connect a person to an object by increasing the feeling of ownership of the object. 


\section{REFERENCES}

Ariely, Dan, Joel Huber, and Klaus Wertenbroch (2005), "When Do Losses Loom Larger than Gains?" Journal of Marketing Research, 42 (May), 134-38.

Ariely, Dan and Itamar Simonson (2003), "Buying, Bidding, Playing, or Competing? Value Assessment and Decision Dynamics in Online Auctions," Journal of Consumer Psychology, 13, 113-23.

Becker, Gordon M., Morris H. DeGroot, and Jacob Marshak (1964), "Measuring Utility by a Single-Response Sequential Method," Behavioral Science, 9 (July), 226-32.

Beggan, James K. (1992), "On the Social Nature of Nonsocial Perception: The Mere Ownership Effect," Journal of Personality and Social Psychology, 62 (2), 229-37.

Brenner, Lyle, Yuval Rottenstreich, Sanjay Sood, and Baler Bilgin (2007), "On the Psychology of Loss Aversion: Possession, Valence, and Reversals of the Endowment Effect," Journal of Consumer Research, 34 (October), 369-76.

Carmon, Ziv and Dan Ariely (2000), "Focusing on the Forgone: How Value Can Appear So Different to Buyers and Sellers," Journal of Consumer Research, 27 (December), 360-70.

Carmon, Ziv, Klaus Wertenbroch, and Marcel Zeelenberg (2003), "Option Attachment: When Deliberating Makes Choosing Feel Like Losing," Journal of Consumer Research, 30 (June), 15-29.

Childers, Terry L., Michael J. Houston, and Susan E. Heckler (1985), "Measurement of Individual Differences in Visual versus Verbal Information Processing," Journal of Consumer Research, 12 (September), 125-34.

Derbaix, Christian (1995), "The Impact of Affective Reactions on Attitudes toward the Advertisement and the Brand: A Step toward Ecological Validity," Journal of Marketing Research, 32 (November), 470-79.

Dhar, Ravi and Klaus Wertenbroch (2000), "Consumer Choice between Hedonic and Utilitarian Goods," Journal of Marketing Research, 37 (1), 60-71.

Franciosi, Robert, Praveen Kujal, Roland Michelitsch, Vernon Smith, and Gang Deng (1996), "Experimental Tests of the Endowment Effect," Journal of Economic Behavior and Organization, 30 (August), 215-26.

Furby, Lita (1978), "Possessions in Humans: An Exploratory Study of Its Meaning and Motivation," Social Behavior and Personality, 6 (1), 49-65.

(1980), "The Origins and Early Development of Possessive Behavior," Political Psychology (Spring), 30-42.

Grohmann, Bianca, Eric R. Spangenberg, and David E. Sprott (2007), "The Influence of Tactile Input on the Evaluation of Retail Product Offerings," Journal of Retailing, 83 (2), $237-$ 46.

Isaacs, Susan (1933), Social Development in Young Children, London: Routledge.

Johnson, Eric J., Gerald Häubl, and Anat Keinan (2007), "Aspects of Endowment: A Query Theory of Value Construction," Journal of Experimental Psychology: Learning, Memory, and Cognition, 33 (3), 461-74.

Johnson, Eric J., John Hershey, Jacqueline Meszaros, and Howard Kunreuther (1993), "Framing, Probability Distortions, and Insurance Decisions," Journal of Risk and Uncertainty, 7, $35-51$.

Kahneman, Daniel, Jack L. Knetsch, and Richard Thaler (1990), "Experimental Tests of the Endowment Effect and the Coase
Theorem," Journal of Political Economy, 99 (December), 1325-48.

Klatzky, Roberta L. and Susan J. Lederman (1992), "Stages of Manual Exploration in Haptic Object Identification," Perception and Psychophysics, 52 (6), 661-70.

(1993), "Toward a Computational Model of ConstraintDriven Exploration and Haptic Object Identification," Perception, 22, 597-621.

Knetsch, Jack L. and Jack A. Sinden (1984), "Willingness to Pay and Compensation Demanded: Experimental Evidence of an Unexpected Disparity in Measures of Value," Quarterly Journal of Economics, 99 (August), 507-21.

Krishna, Aradhna (2006), "Interaction of Senses: The Effect of Vision versus Touch on the Elongation Bias," Journal of Consumer Research, 32 (March), 557-65.

Krishna, Aradhna and Maureen Morrin (2008), "Does Touch Affect Taste? The Perceptual Transfer of Product Container Haptic Cues," Journal of Consumer Research, 34 (6), 807-18.

Lerner, Jennifer S., Deborah A. Small, and George Loewenstein (2004), "Heart Strings and Purse Strings: Carryover Effects of Emotions on Economic Transactions," Psychological Science, 15 (5), 337-41.

McCabe, Deborah Brown and Stephen M. Nowlis (2003), "The Effect of Examining Actual Products or Product Descriptions on Consumer Preference," Journal of Consumer Psychology, 13 (4), 431-39.

Morewedge, Carey K., Lisa L. Shu, Daniel T. Gilbert, and Timothy D. Wilson (2006), "Owning, Not Loss Aversion, Causes the Endowment Effect," working paper, Social Psychology Department, Harvard University, Cambridge, MA.

Nayakankuppam, Dhananjay and Himanshu Mishra (2005), "The Endowment Effect: Rose-Tinted and Dark-Tinted Glasses," Journal of Consumer Research, 32 (2), 390-95.

Novemsky, Nathan and Daniel Kahneman (2005), "The Boundaries of Loss Aversion," Journal of Marketing Research, 42 (May), 119-28.

Peck, Joann (2009), "Does Touch Matter? Insights from Haptic Research in Marketing," in Sensory Marketing: A Confluence of Psychology, Neuroscience and Consumer Behavior Research, ed. Aradhna Krishna, New York: Psychology Press/ Routledge.

Peck, Joann and Terry L. Childers (2003a), "To Have and To Hold: The Influence of Haptic Information on Product Judgments," Journal of Marketing, 67 (April), 35-48.

- (2003b), "Individual Differences in Haptic Information Processing: The 'Need for Touch' Scale," Journal of Consumer Research, 30 (December), 430-42.

- (2006), "If I Touch It I Have to Have It: Individual and Environmental Influences on Impulse Purchasing," Journal of Business Research, 59, 765-69.

_ (2007), "Effects of Sensory Factors on Consumer Behaviors," in Handbook of Consumer Psychology, ed. Frank Kardes, Curt Haugtvedt, and Paul Herr, Mahwah, NJ: Erlbaum.

Peck, Joann and Jennifer Wiggins (2006), "It Just Feels Good: Customers' Affective Response to Touch and Its Influence on Persuasion," Journal of Marketing, 70 (4), 56-69.

Pierce, Jon L., Tatiana Kostova, and Kurt T. Dirks (2001), "Towards a Theory of Psychological Ownership in Organizations," Academy of Management Review, 26 (2), 298-310.

(2003), "The State of Psychological Ownership: Integrating and Extending a Century of Research," Review of General Psychology, 7 (1), 84-107.

Rottenstreich, Yuval and Suzanne B. Shu (2004), "The Connec- 
tions between Affect and Decision Making: Nine Resulting Phenomena," in The Blackwell Handbook of Judgment and Decision Making, ed. Derek Koehler and Nigel Harvey, Oxford: Oxford University Press, 444-63.

Rudmin, Floyd W. and John W. Berry (1987), "Semantics of Ownership: A Free-Recall Study of Property," Psychological Record, 37 (22), 257-68.

Schlosser, Ann E. (2003), "Experiencing Products in a Virtual World: The Role of Goals and Imagery in Influencing Attitudes versus Intentions," Journal of Consumer Research, 30 (September), 377-83.

(2006), "Learning through Virtual Product Experience: The Role of Imagery on True versus False Memories," Journal of Consumer Research, 33 (3), 377-83.

Sen, Sankar and Eric J. Johnson (1997), "Mere-Possession Effects without Possession in Consumer Choice," Journal of Consumer Research, 24 (June), 105-17.
Shiv, Baba and Alexander Fedorikhin (1999), "Heart and Mind in Conflict: The Interplay of Affect and Cognition in Consumer Decision Making," Journal of Consumer Research, 26 (December), 278-92.

Strahilevitz, Michal A. and George Loewenstein (1998), "The Effect of Ownership History on the Valuation of Objects," Journal of Consumer Research, 25 (December), 276-89.

Thaler, Richard (1980), "Toward a Positive Theory of Consumer Choice," Journal of Economic Behavior and Organization, 1, 36-90.

(1985), "Mental Accounting and Consumer Choice," Marketing Science, 4 (3), 199-214.

Wolf, James R., Hal R. Arkes, and Waleed A. Muhanna (2005), "Is Overbidding in Online Auctions the Result of a PseudoEndowment Effect?" working paper, Social Science Research Network. 